\title{
VIEWPOINT
}

\section{Stents are used too often}

We can forgive a man for making a useful thing as long as he does not admire it. The only excuse for making a useless thing is that one admires it intensely.

\section{The Picture of Dorian Gray-Oscar Wilde}

Although percutaneous treatment of focal coronary artery lesions by conventional balloon angioplasty has gained widespread acceptance, it remains limited by the persistence of two problems: abrupt vessel closure early after intervention and restenosis during follow up. Stenting has become an effective treatment for abrupt or threatened vessel closure during conventional angioplasty. Furthermore, prospective trials have demonstrated that its clinical efficacy is superior to that of conventional balloon angioplasty for primary restenosis prevention in focal lesions of native coronary arteries. ${ }^{12}$ Some cardiologists consider stents as a breakthrough technology in that they might not only reduce restenosis rates but also improve most angiographic results achieved by conventional balloon angioplasty. The policy to achieve an optimal or even super-optimal angiographic lumen by scaffolding the artery with mechanical implants has dramatically reduced the phenomena of early elastic recoil as it virtually abolished the elasticity of the stented vascular segment.

In most laboratories where interventional procedures are commonly performed, at least $40-50 \%$ of cases involve the permanent implantation of a stent. This veritable "see change" or "oculomotoric policy" is the most radical transformation in the field of interventional cardiology since its birth in 1977. Indeed, metal prosthetic implants in the coronary artery circulation have become an extraordinarily routine procedure. At least 350000 patients worldwide had at least one coronary stent implanted in $1997 .^{3}$

\section{Historical aspects}

The first results of the implantation of coronary stents were published in 1987; these stents were primarily intended to be used for the prevention of restenosis following balloon dilatation. ${ }^{4}$ Abrupt vessel closure and treatment of saphenous vein graft lesions were also important indications for the placement of a stent. Although there was a steadily growing interest among interventional cardiologists, there was only a moderate growth in the number of stents implanted. Several factors may have accounted for this moderate growth in stent treatment in the early years, among them subacute stent thrombosis, difficulties in accurate stent positioning, and bleeding problems were three major reasons not to use stents but to trust in the efficacy of balloon angioplasty alone. With technical improvements and alterations in the medical regimen before and after stent placement, randomised trials comparing stenting with angioplasty were initiated for primary restenosis prevention and sudden or threatened vessel closure during angioplasty. The results of these trials resulted in a dramatic increase of the number of stents implanted. While stenting was reserved for specific indications until the early '90s, it was felt to be necessary in many situations that were traditionally treated by conventional balloon angioplasty alone. ${ }^{5}$

\section{Indications and contraindications}

Stents are now used in $30-60 \%$ of all coronary angioplasty procedures at most interventional centres. Obviously, there is a significant mismatch between clinical practice and trial based evidence. The results of the few available randomised trials have been enthusiastically extrapolated to almost every patient and lesion subset. ${ }^{67}$

There is currently solid evidence from randomised and observational trials to support the following indications:

- treatment of abrupt, and prevention of threatened, coronary occlusion after balloon angioplasty ${ }^{8-11}$

- primary reduction in restenosis in vessels with a diameter $>3 \mathrm{~mm}$, particularly in the left anterior descending artery with a suboptimal angiographic result after balloon angioplasty. ${ }^{12}{ }^{12}$

Preliminary results of ongoing randomised trials as well as observational data favour the combination of balloon angioplasty and stenting for the treatment of:

- saphenous vein graft disease $\mathrm{e}^{1314}$

- chronic total occlusions. ${ }^{15}$

From a scientific point of view, it seems wise to restrict the clinical use of intracoronary stents to these indications. More data from large randomised trials should be awaited before the routine use of stents can be recommended in clinical situations such as acute myocardial infarction, or in lesion subsets such as ostial disease, long lesions, calcified, complex lesions, left main stenosis, small vessels, diffuse disease or bifurcational lesions. In particular, stent use should be avoided in vessel segments that are suitable for bypass graft implantations in patients with two or triple vessel disease. Significant focal disease of the left anterior descending artery can effectively be treated by the new MIDCAB intervention, in which this vessel is supplied via the left internal mammaria. In an era of minimally invasive techniques it can be anticipated that this surgical procedure may lead to long term results that will compare favourably to other percutaneous interventional approaches. Finally, it remains questionable whether repeat stenting for in-stent restenosis is of any clinical value. ${ }^{7}$

\section{Questions arising from coronary stenting}

Although the proliferative response of stented arterial segments is pronounced and prolonged compared with balloon angioplasty, there is a somewhat better long term achievement of vessel lumen as demonstrated by quantitative coronary angiography. Data from all angiographically substantiated trials support the strategy of maximising acute luminal gain by whatever interventional means possible. It has been demonstrated that sizing of balloon diameters by intravascular ultrasound according to the diameter of the external elastic membrane results in a pronounced angiographic oversizing of balloons. However, these studies have also shown that the policy of vessel size adapted, ultrasound guided balloon angioplasty results in sufficient mechanical remodelling of the vessel, which enables accommodation of a rather low luminal loss, and 
results in a low restenosis rate. ${ }^{16}$ The increased arterial distensibility resulting from dissection and "overstretch" injury might also contribute to an improved long term angiographic outcome using the vessel size adapted technique compared with vessels treated with the conventional approach. ${ }^{16}$

In contrast to conventional balloon angioplasty, intravascular ultrasound guided balloon angioplasty or other plaque debulking techniques, such as atherectomy, rotational atherectomy or laser angioplasty, stents are permanent implants that will remain in their position once they are delivered at the lesion site. Despite their beneficial effects on early and late luminal loss, stent loss, stent migration, stent infection, and metal fatigue all constitute potential problems that cannot be answered during a follow up of several months. Over time, there will be millions of patients with coronary stents, and if long term assessment is not done in randomised trials we will not know the extent nor the incidence of late complications. In view of these unforeseeable results, we must make every effort to avoid repeating the uncertainty engendered with the Shiley prosthetic heart valve, the Teletronics pacemakers, or silicon breast implants. ${ }^{3}$

To avoid potential hazards associated with stents we wish to make two main points in this article (and the systematic review of the randomised evidence on which it is based). First, we raise the question about the generalisability of the results of randomised trials, such as the Benestent and the Stress trials: is it wise to assume that the benefits of stenting in highly selected patient populations, tested in some of the very best centres in the United States and Europe, would be the same when used in everyday clinical practice worldwide? Second, is it wise to base decision making for more than one million people with disabling angina undergoing percutaneous angioplasty on randomised trials with just several hundred patients? Viewed in this more global context, a sample size of several hundred patients may be enough to achieve statistical significance, but may not be large enough to be the basis for a global health care policy.

Despite clear cut advantages of stenting in several clinical situations it should be remembered that the angiographic picture of the coronary artery having very recently undergone intervention constitutes only a moment during the life of our patient. In view of the rather good prognosis of coronary artery disease in most patients, stents must show their durability not only for months and several years, but for decades. Many patients are given stents not on the basis of science or evidence-based medicine. The admiration of the acute angiographic result following the placement of a stent should not abolish critical thinking in cardiac catheterisation and intervention.

K K HAASE

A BAUMBACH

K R KARSCH

University of Tuebingen,

Medical Clinic III,

Otfried Muellerstrasse 10,

72076 Tuebingen, Germany

1 Serruys PW, de Jaegere P Kiemeneij F, et al. A comparison of balloon-expandable-stent implantation with balloon angioplasty in patients with coronary artery disease. N Engl f Med 1994;331:489-95.

2 Fischman DL, Leon MB, Baim DS, et al. A randomized comparison of coronary stent-placement and balloon angioplasty in the treatment of coronary stent-placement and balloon angioplasty in the

3 Topol EJ. Validation for coronary stenting: a permanent implant for Topol EJ. Validation for coronary stenting: a permant

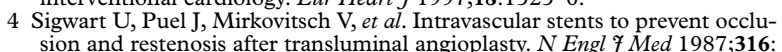
sion and $701-6$.

5 Wickelgren I. New devices are helping transform coronary care. Science 1996;272:668-70.

6 Eeckhout E, Kappenberger L, Goy J-J. Stents for intracoronary placement: current status and future directions. $\mathcal{f}$ Am Coll Cardiol 1996;27:757-65.

7 Balcon R, Beyar R, Chierchia S, et al. Recommendations on stent manufacture, implantation and utilization. Eur Heart f 1997;18:1536-47.

8 Sigwart U, Urban P, Golf S, et al. Emergency stenting for acute occlusion after coronary balloon angioplasty. Circulation 1988;78:1121-7.

9 George BS, Voorhees WD III, Roubin GS, et al. Multicenter investigation of coronary stenting to treat acute or threatened closure after percutaneous transluminal coronary angioplasty: clinical and angiographic outcomes. $\mathcal{f}$ Am Coll Cardiol 1993;22:135-43.

10 Schömig A, Kastrati A, Mudra H, et al. Four-year experience with PalmazSchatz stenting in coronary angioplasty complicated by dissection with Schatz stenting in coronary angioplasty complicated by dissection
threatened or present vessel closure. Circulation 1994;90:2716-24.

11 Dean LS, George CJ, Roubin GS, et al. Bailout and corrective use of Gianturco-Roubin flex stents after percutaneous transluminal coronary angioplasty. $\mathcal{F} \mathrm{Am}$ Coll Cardiol 1997;29:934-40.

12 Versaci F, Gaspardone A, Tomai F, et al. A comparison of coronary-artery stenting with angioplasty for isolated stenosis of the proximal left anterior descending coronary artery. N Engl f Med 1997;336:817-22.

13 Strauss BH, Serruys PW, Bertrand ME, et al. Qualitative angiographic follow-up of the coronary Wallstent in native vessels and bypass grafts. $A m$ f Cardiol 1992;69:475-81.

14 de Jaegere PP, van Domburg RT, de Feijter PJ, et al. Long-term clinical outcome after stent implantation in saphenous vein grafts. 7 Am Coll Cardiol 1996;28:89-96.

15 Sirnes PA, Golf S, Myreng Y, et al. Stenting in chronic coronary occlusion (SICCO): a randomized, controlled trial of adding stent implantation after successful angioplasty. $\mathcal{F}$ Am Coll Cardiol 1996;28:1444-51.

16 Haase KK, Athanasiadis A, Mahrholdt H, et al. Acute and one year follow-up results after vessel size adapted PTCA using intracoronary ultrasound. Eur Heart F 1998;19:263-72. 